\title{
Altered Body Weight Regulation in CK1E Null and tau Mutant Mice on Regular Chow and High Fat Diets
}

\author{
Lili Zhou, ${ }^{1,2}$ Keith C. Summa, ${ }^{1,2}$ Christopher Olker, ${ }^{1,2}$ Martha H. Vitaterna,, \\ and Fred W. Turek ${ }^{1,2}$ \\ ${ }^{1}$ Center for Sleep and Circadian Biology, Northwestern University, Evanston, IL 60208, USA \\ ${ }^{2}$ Department of Neurobiology, Northwestern University, Evanston, IL 60208, USA
}

Correspondence should be addressed to Fred W. Turek; fturek@northwestern.edu

Received 30 November 2015; Revised 1 March 2016; Accepted 9 March 2016

Academic Editor: Francine Durocher

Copyright (C) 2016 Lili Zhou et al. This is an open access article distributed under the Creative Commons Attribution License, which permits unrestricted use, distribution, and reproduction in any medium, provided the original work is properly cited.

\begin{abstract}
Disruption of circadian rhythms results in metabolic dysfunction. Casein kinase 1 epsilon $(C K 1 \varepsilon)$ is a canonical circadian clock gene.

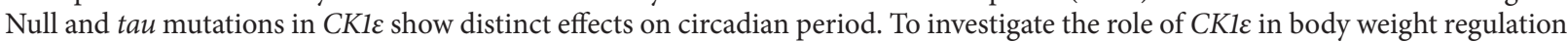
under both regular chow (RC) and high fat (HF) diet conditions, we examined body weight on both RC and HF diets in CK1 $\varepsilon^{-/-}$ and $C K 1 \varepsilon^{\text {tau/tau }}$ mice on a standard $24 \mathrm{hr}$ light-dark (LD) cycle. Given the abnormal entrainment of CK1 $\varepsilon^{\text {tau/tau }}$ mice on a $24 \mathrm{hr} \mathrm{LD}$ cycle, a separate set of CK1 $\varepsilon^{\text {tau/tau }}$ mice were tested under both diet conditions on a $20 \mathrm{hr}$ LD cycle, which more closely matches their endogenous period length. On the RC diet, both $C K 1 \varepsilon^{-/-}$and $C K 1 \varepsilon^{\text {tau/tau }}$ mutants on a $24 \mathrm{hr} \mathrm{LD}$ cycle and CK1 $\varepsilon^{\text {tau/tau }}$ mice on a $20 \mathrm{hr}$ LD cycle exhibited significantly lower body weights, despite similar overall food intake and activity levels. On the HF diet, $C K 1 \varepsilon^{\text {tau/tau }}$ mice on a $20 \mathrm{hr}$ LD cycle were protected against the development of HF diet-induced excess weight gain. These results provide additional evidence supporting a link between circadian rhythms and energy regulation at the genetic level, particularly highlighting CK1 $\varepsilon$ involved in the integration of circadian biology and metabolic physiology.
\end{abstract}

\section{Introduction}

The coordination of daily rhythms in feeding behavior, body temperature, and energy storage and utilization across the $24 \mathrm{hr}$ light-dark (LD) cycle is critical in maintaining homeostasis. It has been well established that circadian rhythms are controlled by endogenous circadian clock genes [1]. Core clock genes, such as Clock, Bmal1, Period (Per), and Cryptochrome (Cry), are key components of the transcriptional/translational feedback loop, which is considered to be the major mechanism underlying the generation of circadian rhythms [2]. Based on gene expression profiling studies, approximately $3 \%-20 \%$ of the transcriptome in any given tissue exhibits circadian oscillation, and a large proportion of the rhythmically regulated transcripts are involved in metabolic function [3]. In addition, the discovery that clock genes function in peripheral tissues involved in metabolism, such as liver, fat, heart, and muscle, provides further support that circadian and metabolic processes are tightly linked [4, 5].

Accumulating evidence from both human and animal studies has strongly supported an important role for circadian rhythms in the regulation of metabolism. Shift workers have a higher incidence of diabetes, obesity, cancer, and cardiovascular diseases [6-8]. In clinical studies, forced misalignment of behavioral (i.e., sleep/wake) and circadian cycles in human subjects causes metabolic and endocrine abnormalities, including decreases in leptin and increases in glucose and insulin [9]. In rodents, genetic disruption of the molecular clock system leads to a variety of metabolic abnormalities, including obesity and metabolic syndrome in Clock mutant mice [10] and Per2 deficient mice [11]. In contrast, mutant mice lacking the core clock gene Bmall, either globally or exclusively in liver, have a lean phenotype $[5,12,13]$. Chronic circadian disruption, achieved by housing wild-type mice in a $20 \mathrm{hr}$ LD cycle that is incongruous 
with their endogenous $\sim 24 \mathrm{hr}$ circadian period, results in accelerated weight gain and obesity, as well as dysregulation of metabolic hormones [14].

Casein kinase 1 epsilon $(C K 1 \varepsilon)$, a member of the serine/threonine protein kinase family, is a canonical circadian gene which regulates circadian rhythms through posttranslational modification of the PER and CRY proteins [15]. In the kinase domain of $C K 1 \varepsilon$, a $\mathrm{C}$ to $\mathrm{T}$ single nucleotide transition results in a missense point mutation (tau mutation) of a conserved amino acid residue 178 (R178C), which causes profound changes in circadian organization in hamsters and mice, with a 4-hour decrease in the free-running period in homozygous mutants in constant darkness (DD) [16, 17]. Furthermore, the intrinsic $20 \mathrm{hr}$ period length in tau mutant mice prevents stable entrainment to a conventional $24 \mathrm{hr} \mathrm{LD}$ cycle [15]. Another mouse model for CK1s is the null mutant, which was developed using the loxP-Cre strategy to create a premature codon induced by frameshift in the CK1 $\varepsilon$ gene. In contrast to tau mutant mice, null mutant mice exhibited a significant but very mild lengthening of the circadian period [18].

Despite extensive evidence supporting a tight relationship between circadian rhythms and metabolism, studies examining the role of CK1E in metabolic function remain limited. Previous studies in hamsters have demonstrated a significant impact of the CK1E tau mutation on body weight regulation in males, with homozygous mutants weighing significantly less than wild-types [19-21]. Both tau mutant hamsters and tau mutant mice exhibit increased metabolic rates $[18,20]$. Despite these findings, it is unknown whether tau mutant mice exhibit a reduction in body weight. In addition, no previous study has examined other mutations in $C K 1 \varepsilon$; thus, no comparison between different CK1ع mutants has been made. Furthermore, it is unclear whether the metabolic changes in CKle tau mutant hamsters are caused by an accelerated circadian pacemaker, as opposed to other pleiotropic effects of the mutant allele. It is also unknown whether tau mutants demonstrate altered body weight regulation on a high fat diet (HF) as they do on regular chow (RC).

Therefore, we used both $C K 1 \varepsilon^{-/-}$and $C K 1 \varepsilon^{\text {tau/tau }}$ mutant mice as genetic tools to investigate the impact of these two mutations on body weight regulation in a $24 \mathrm{hr} \mathrm{LD}$ cycle under two different diet conditions: RC and HF. In addition, because of the abnormal entrainment in $C K 1 \varepsilon^{\text {tau/tau }}$ mice (not $\mathrm{CK} 1 \varepsilon^{-/-}$mice) on a $24 \mathrm{hr} \mathrm{LD}$ cycle, a separate set of CK1 $\varepsilon^{\text {tau/tau }}$ mice were tested in a $20 \mathrm{hr}$ LD cycle, which more closely matches their endogenous period length and permits patterns of entrainment comparable to those of wild-types on a standard $24 \mathrm{hr}$ LD cycle. This was done to investigate whether the phenotype observed in $C K 1 \varepsilon^{\text {tau/tau }}$ mice on a $24 \mathrm{hr}$ LD cycle was simply an artifact of the altered entrainment. Our results indicate that, on a $\mathrm{RC}$ diet, both CK1E null and tau mutations on a $24 \mathrm{hr}$ LD cycle, as well as the CK1ع tau mutation on a $20 \mathrm{hr}$ LD cycle, exhibit significant effects on body weight, with mutant mice weighing less than wild-types. In contrast, on the HF diet, neither mutation on a $24 \mathrm{hr}$ LD cycle led to a significant difference from wild-types.
Remarkably, a $20 \mathrm{hr}$ LD cycle, which restores normal light entrainment in $C K 1 \varepsilon^{\text {tau/tau }}$ mice, provides resistance to excess body weight gain induced by a HF diet.

\section{Materials and Methods}

2.1. Animals and Experimental Protocol. All mutant animals used in this experiment were coisogenic C57BL/6J mice. The generation of these mutants has been described previously [18]. For all experiments, male wild-type $\left(C K 1 \varepsilon^{+/+}\right), C K 1 \varepsilon$ null mutant $\left(\mathrm{CK}_{1} \varepsilon^{-/-}\right)$, and tau mutant $\left(C K 1 \varepsilon^{\text {tau/tau}}\right)$ mice were maintained in standard mouse cages with food and water available ad libitum on a conventional $12 \mathrm{hr}$ light : $12 \mathrm{hr}$ dark LD cycle (LD 12:12; lights on at 0600, lights off at 1800; 300 lux and $22-24^{\circ} \mathrm{C}$ ambient temperature). Until the beginning of the study, mice were group-housed and fed a RC diet $(16 \%$ kcal from fat, $27 \% \mathrm{kcal}$ from protein, and $57 \% \mathrm{kcal}$ from carbohydrate; 7012 Teklad LM-485 Mouse/Rat Sterilizable Diet, Harlan Laboratories, Inc., Indianapolis, IN). At the age of 10 weeks, mice were transferred to individual cages under the same lighting and environmental conditions described above. The animals were randomized into experimental groups and fed either RC $\left(C K 1 \varepsilon^{+/+}, n=18 ; C K 1 \varepsilon^{-/-}, n=17\right.$; CK1 $\left.\varepsilon^{\text {tau/tau }}, n=13\right)$ or HF diet ( $45 \%$ kcal from fat, $20 \%$ $\mathrm{kcal}$ from protein, and 35\% kcal from carbohydrate; D12451, Research Diets, Inc. New Brunswick, NJ; CKle $\varepsilon^{+/+}, n=16$; $\left.C K 1 \varepsilon^{-/-}, n=13 ; C K 1 \varepsilon^{\text {tau/tau }}, n=16\right)$.

Body weight was recorded weekly for 6 weeks. Food consumption was measured daily for 7 consecutive days in the second week of the experiment. A glucose tolerance test and an insulin tolerance test were performed on the seventh and eighth weeks, respectively, as described below. On the ninth week, serum samples, obtained by tail bleed, were collected 6 hours after light onset (by convention, referred to as Zeitgeber time (ZT) 6) from mice that had been fasted for 6 hours. At the end of the experiment, mice were euthanized (without fasting) at ZT6, and gonadal fat pads were harvested for analysis. A separate group of age-matched $C K 1 \varepsilon^{\text {tau/tau }}$ mutant mice were individually housed and fed either RC $(n=$ $10)$ or HF $(n=8)$ diet. All procedures for this group were the same as above, except they were maintained on a $20 \mathrm{hr}$ LD cycle (LD 10:10) for the duration of the experimental protocol. All procedures and protocols were approved in advance by the Institutional Animal Care and Use Committee of Northwestern University.

2.2. Locomotor Activity. Five or six mice of each genotype from a separate group of mice were singly housed in individual cages outfitted for locomotor activity analysis via detection of infrared beam breaks. These mice were fed either RC or HF diet under LD 12:12 or LD 10:10 cycle for 10 days and were used exclusively for locomotor activity analysis (i.e., they were not included in the body weight measurements or other metabolic analyses). Beam breaks were recorded in 6 min bins using the Chronobiology Kit (Stanford Software Systems, Stanford, CA, USA) and were analyzed using the ClockLab software (Actimetrics, Wilmette, IL, USA). 
2.3. Body Temperature. Body temperatures were measured in 8-16-week-old male mice with a rectal thermometer $(4600$ thermometer, Measurement Specialties, Beavercreek, $\mathrm{OH}$ ) inserted $1.7 \mathrm{~cm}$ in the middle of day time.

2.4. Blood Collection and Serum Insulin Analysis. Mice were transferred to clean cages at ZT0 to fast for 6 hours, during which access to water was unrestricted. At ZT6, tails were clipped to obtain blood samples for analysis and serum isolation. Briefly, a small $(1 \mathrm{~mm})$ cut was made at the end of the tail and about $50 \mu \mathrm{L}$ of blood was obtained by gentle massage using tail blood collection tubes (BD Vacutainer Plus plastic serum tube, $2 \mathrm{~mL}$, red top, \#367820, BD Diagnostics, Franklin Lakes, NJ). Mice were then returned to their home cages. At room temperature, blood was incubated in an upright position for $45 \mathrm{~min}$ and then spun in a centrifuge for $6 \mathrm{~min}$ at $2000 \times \mathrm{g}$. The supernatant (serum) was removed, frozen, and stored at $-80^{\circ} \mathrm{C}$ until future analysis. Serum insulin levels were determined by ELISA (Ultra Sensitive Mouse Insulin ELISA Kits, Crystal Chem Inc., Downers Grove, IL) according to the manufacturer's instructions. Blood glucose was determined as described below.

2.5. Glucose and Insulin Tolerance Tests. For the glucose tolerance test (GTT), mice were fasted for 6 hours (ZT0 to ZT6), after which baseline blood glucose levels were determined from a blood sample obtained from the tail of each mouse. A small $(1 \mathrm{~mm})$ cut was made at the end of the tail and a drop of blood was deposited onto a glucometer strip (Abbott Laboratories, Abbott Park, IL) by gentle massage for assessment of blood glucose level. Mice were then immediately injected intraperitoneally with $1.0 \mathrm{~g} / \mathrm{kg}$ body weight of glucose (G8769, Sigma-Aldrich, St. Louis, MO). Additional blood samples and blood glucose readings were obtained via massage of the tail nick at 30,60, and $120 \mathrm{~min}$ after the injection. Upon completion of the experiment, mice were returned to their home cages. Results are expressed as percentage of baseline glucose. Area under the curve (AUC) values were calculated by the trapezoidal rule.

For the insulin tolerance test (ITT), mice were fasted for 2 hours (ZT4 to ZT6), after which baseline blood glucose was measured as described above. Immediately after the baseline blood glucose sample was obtained, 0.75 units $/ \mathrm{kg}$ body weight of regular human insulin Humulin ${ }^{\circledR}$ R U-100 (Eli Lilly, Indianapolis, IN; insulin was diluted to 1:1000 (0.1 units $/ \mathrm{mL}$ ) with sterile diluent) was injected intraperitoneally. After the insulin injection, blood glucose was sampled at 30, 60,90 , and $120 \mathrm{~min}$, as described above. Upon completion of the experiment, animals were returned to their home cages. Results are expressed as percentage of baseline glucose. Area under the curve (AUC) values were calculated by the trapezoidal rule.

2.6. Statistics. All statistical analysis was performed using $\mathrm{R}$ software (http://www.r-project.org/) [22]. Time course data of body weight, GTT, and ITT on each diet were analyzed using repeated measures ANOVA with genotype as the between-subject factor and time as the within-subject variable. Following a significant result on repeated measures ANOVA, single time point comparisons were made by Benjamini-Hochberg multiple comparison tests. All the other comparisons between genotypes and diets were conducted via two-way ANOVA, with Benjamini-Hochberg post hoc tests performed where appropriate for multiple comparisons. Group values are expressed as mean \pm SEM. Significant differences were defined as $p<0.05$.

\section{Results}

3.1. Altered Body Weight Regulation in CK1ع Mutants. Individually caged young adult (10-week) male mice were given either regular chow (RC) or high fat (HF) diet for the entire experimental protocol. After 6 weeks on RC, both $C K 1 \varepsilon^{-/-}$and $C K 1 \varepsilon^{\text {tau/tau }}$ mice exhibited a significantly lower body weight than $C K 1 \varepsilon^{+/+}$mice, approximately $15 \%$ less (Figure 1(a); CK1 $\varepsilon^{+/+}=29.38 \pm 1.39 \mathrm{~g}, C K 1 \varepsilon^{-/-}=24.91 \pm$ $0.98 \mathrm{~g}$, and $C K 1 \varepsilon^{\text {tau } / \mathrm{tau}}=24.69 \pm 1.67 \mathrm{~g}$ ). Because the body weight of $C K 1 \varepsilon^{+/-}$and $C K 1 \varepsilon^{+/ t a u}$ mice did not differ from wild-type mice (data not shown), the present study only focuses on results from homozygous mutants. Additional analyses indicated that the body weight differences between $C K 1 \varepsilon^{+/+}$mice and both $C K 1 \varepsilon$ mutant mice were as early as the age of 3 weeks immediately after weaning (see Figure S1 in Supplementary Material available online at http://dx.doi.org/10.1155/2016/4973242). CK1 $\varepsilon^{-/-}$mice had significantly lower body weight than wild-type mice throughout the entire period of experiment. However, the stable body weight changes of $C K 1 \varepsilon^{\text {tau/tau }}$ mice compared to wildtype mice were only observed after week 8 . To avoid this developmental fluctuation, we focused on the body weight only during adulthood.

Due to abnormal entrainment patterns and the mismatch between endogenous period length and the $24 \mathrm{hr}$ LD cycle in homozygous tau mutants [15], we were interested in whether restoration of entrainment and resonance between the environmental cycle length and endogenous period in tau mutants would impact body weight regulation. $\mathrm{CK} 1 \varepsilon^{-/-}$ mice, whose endogenous period is very close to $24 \mathrm{hr}$, have normal entrainment, so their phenotype was less likely to be affected by the entrainment. Therefore, we focused on only $C K 1 \varepsilon^{\text {tau/tau }}$ mice and maintained two separate groups of tau mutant mice on RC and HF diet, respectively, on a $20 \mathrm{hr}$ LD cycle. We observed that the CK1 $\varepsilon^{\text {tau/tau }}$ mice on a $20 \mathrm{hr} \mathrm{LD}$ cycle maintain significantly reduced body weight compared to wild-type mice on a $24 \mathrm{hr}$ LD cycle on RC diet (Figure 1(a)).

On the HF diet, mice of all genotypes gained significantly more weight than the ones on the RC diet, as expected (Figure 1(c)). Significant differences were not evident between mutant and wild-type mice on a $24 \mathrm{hr}$ LD cycle (Figure 1(b)). Intriguingly, when HF-fed CK1 $\varepsilon^{\text {tau/tau }}$ mice were housed on a $20 \mathrm{hr} \mathrm{LD}$ cycle, the rate of body weight gain was reduced compared to other genotypes, resulting in a significantly lower weight gain after 6 weeks on the diet (Figure 1(c); $C K 1 \varepsilon^{+/+}=15.5 \pm 1.2 \mathrm{~g}, C K 1 \varepsilon^{-/-}=14.0 \pm 0.8 \mathrm{~g}, C K 1 \varepsilon^{\text {tau } / \mathrm{tau}}=$ $16.4 \pm 1.4 \mathrm{~g}$, and CKle $\varepsilon^{\text {tau } / \mathrm{tau}}$ on $20 \mathrm{hr} \mathrm{LD}=9.6 \pm 1.1 \mathrm{~g}$ ). 


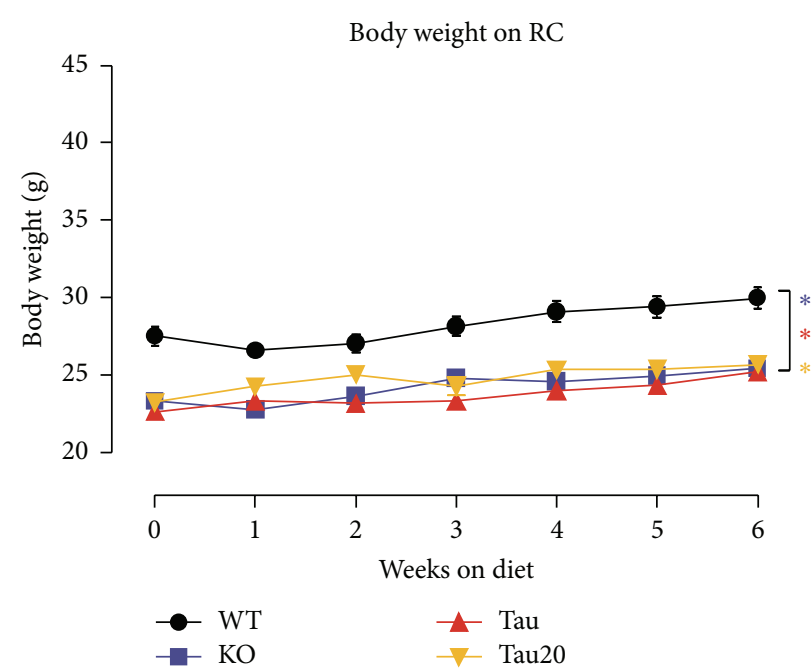

(a)

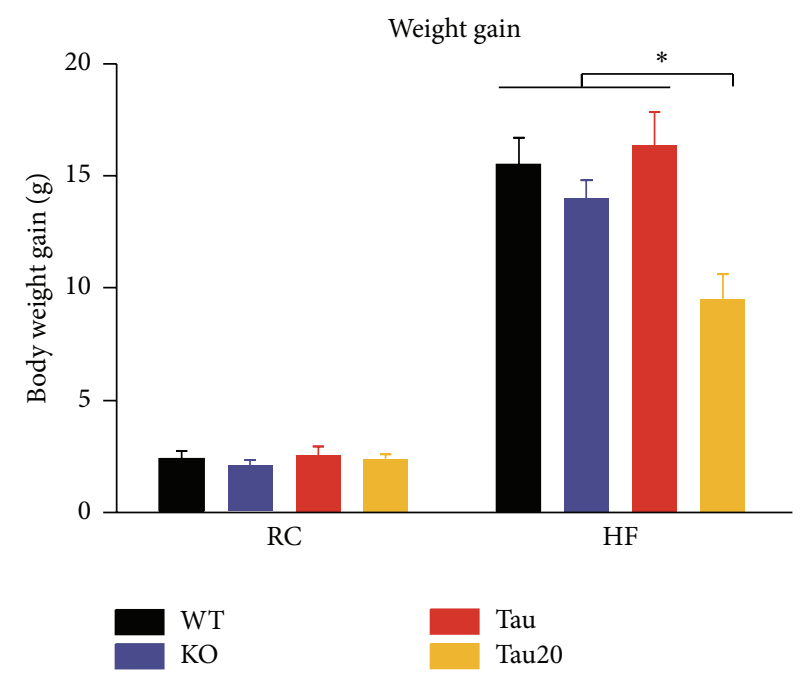

(c)

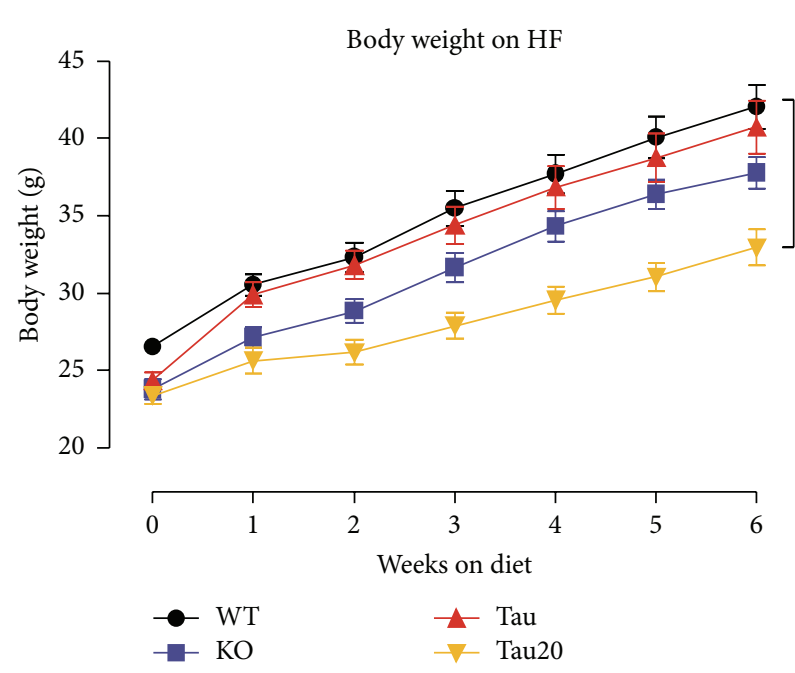

(b)

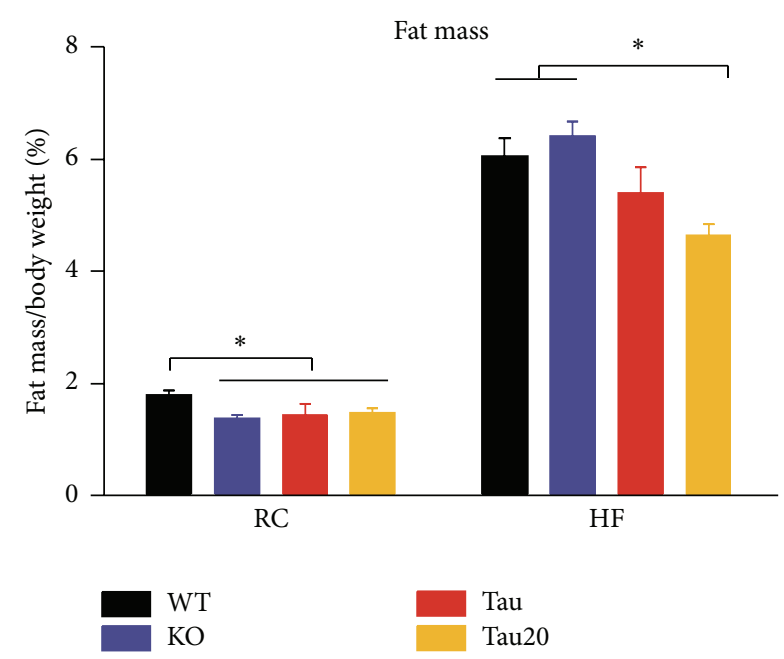

(d)

FIGURE 1: Altered body weight and fat mass in CK1ع mutant mice. (a) Growth curves of mice on RC diet. (b) Growth curves of mice on HF diet. (c) Total body weight gain after six weeks of either RC or HF diet. Body weight gain was calculated by subtracting the baseline weight at the beginning of the diet experiment from weight at the end of the diet experiment. (d) The gonadal fat pads from mice fed either RC or HF diet were weighed at the end of study. CKle ${ }^{+/+}$(black), $C K 1 \varepsilon^{-/-}$(blue), and CK1 $\varepsilon^{\text {taultau }}$ (red) mice were on a 24 hr LD cycle; CK1 $\varepsilon^{\text {taultau }}$ mice kept on a $20 \mathrm{hr}$ LD cycle are represented in yellow. Mean values are presented for each group, with error bars representing SEM. Asterisks indicate significant differences between groups $(p<0.05)$.

In agreement with the observed effects on body weight, we also observed reduced gonadal fat pad weight in CK1ع mutant mice. As shown in Figure 1(d), on RC, both $\mathrm{CKl}^{-/-}$ and $C K 1 \varepsilon^{\text {tau/tau }}$ mutant mice on a $24 \mathrm{hr} \mathrm{LD}$ cycle, as well as CKletaultau on a $20 \mathrm{hr}$ LD cycle, had a significantly reduced proportion of gonadal fat pad mass to total body weight $\left(C K 1 \varepsilon^{+/+}=1.79 \pm 0.09 \%, C K 1 \varepsilon^{-/-}=1.37 \pm 0.05 \%\right.$, $C K 1 \varepsilon^{\text {tau } / \text { tau }}=1.44 \pm 0.19 \%$, and $C K 1 \varepsilon^{\text {tau } / \text { tau }}$ on $20 \mathrm{hr} \mathrm{LD}=$ $1.48 \pm 0.07 \%$ ). On the HF diet (Figure $1(\mathrm{~d})$ ), mice of all genotypes exhibited a pronounced increase in percentage of gonadal fat pad weight, as expected; however, no significant differences were observed between $C K 1 \varepsilon^{-/-}, C K 1 \varepsilon^{\text {tau/tau }}$, and $\mathrm{CKl}^{+/+}$mice on a $24 \mathrm{hr} \mathrm{LD}$ cycle. Interestingly, as with body weight, HF-fed CK1 $\varepsilon^{\text {tau/tau }}$ mutant mice on a $20 \mathrm{hr}$ LD cycle had a significant reduction in the percentage of gonadal fat pad weight, compared to HF-fed wild-type mice $\left(\mathrm{CKl}^{+/+}=\right.$ $6.05 \pm 0.32 \%$ and $C K 1 \varepsilon^{\text {taultau }}$ on $20 \mathrm{hr} \mathrm{LD}=4.64 \pm 0.21 \%$ ). With respect to the absolute mass of the gonadal fat pad, identical results were observed (data not shown).

3.2. Altered Diurnal Feeding Behavior and Locomotor Activity in CK1s Mutants. To determine whether the reduced body weight in CK1s mutants was due to decreased food intake, we examined food consumption under RC and HF conditions. Total daily overall caloric intake did not differ between genotypes on $24 \mathrm{hr}$ LD cycle (Figure 2(a)). However, 


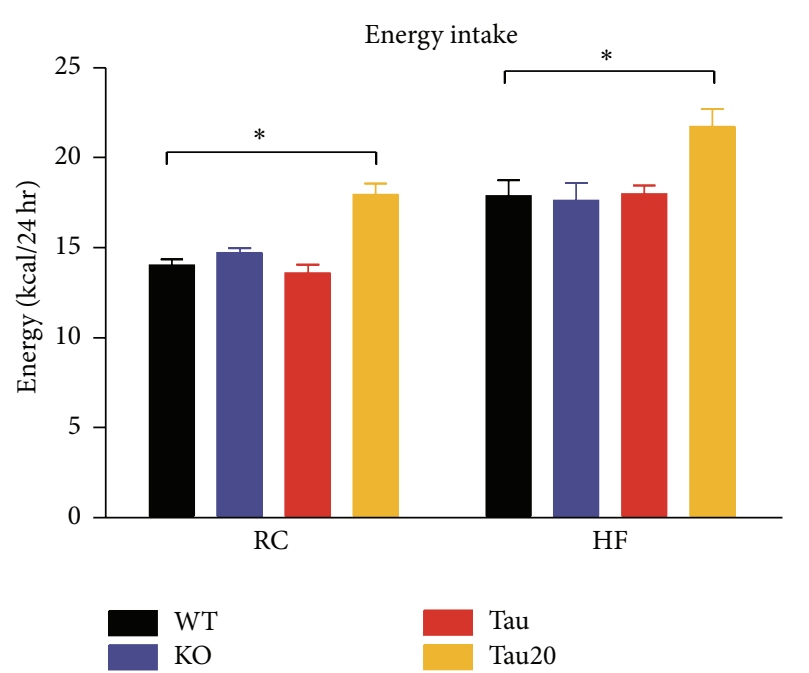

(a)

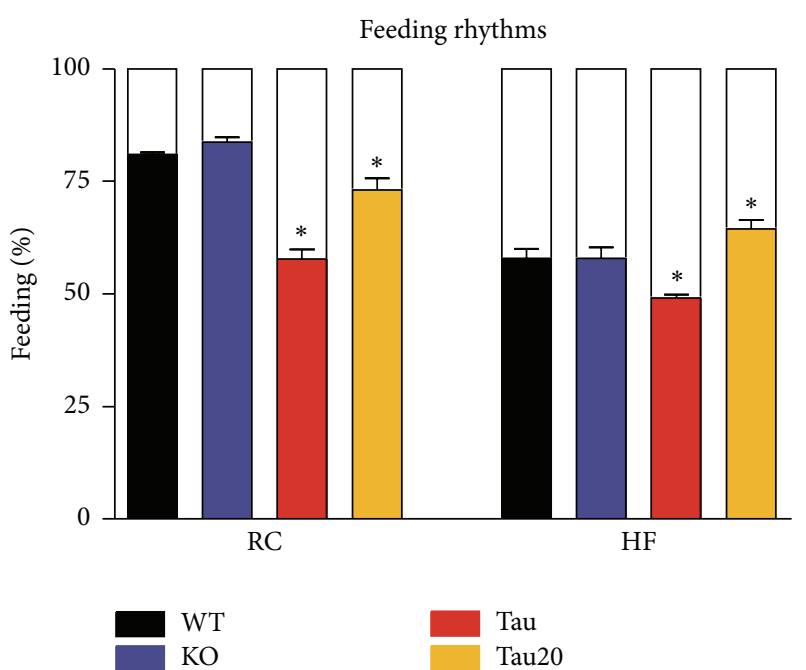

(b)

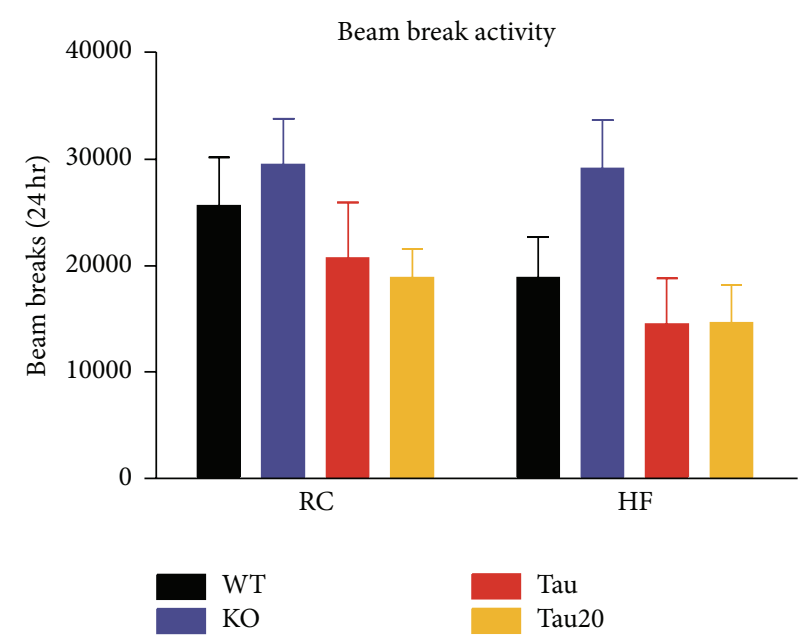

(c)

FIGURE 2: Altered diurnal feeding behaviors in CK1ع mutant mice. (a) The diet, but not the genotype, has a significant effect on daily calorie intake. Energy intake was expressed as the average kilocalories consumed during each $24 \mathrm{hr}$ period. (b) Percentage of calorie intake in light and dark periods. The top proportion, in white, represents the percentage of calorie intake in the light period. The bottom proportion, in different colors, represents the percentage of calorie intake in the dark period. Results were compared between mutants and wild-type controls on the same diet. (c) Locomotor activity of mice fed either RC or HF diet. The activity was expressed as the average beam breaks during each $24 \mathrm{hr}$ period. $C K 1 \varepsilon^{+/+}$(black), $C K 1 \varepsilon^{-/-}$(blue), and CKle $\varepsilon^{\text {tau/tau }}$ (red) mice were on a $24 \mathrm{hr}$ LD cycle; CK1 $\varepsilon^{\text {taultau }}$ mice represented in yellow were on a $20 \mathrm{hr}$ LD cycle. Mean values are presented for each group, with error bars representing SEM. Asterisks indicate significant differences between groups $(p<0.05)$.

CKle $\varepsilon^{\text {tau/tau }}$ mice on a $20 \mathrm{hr}$ LD cycle consumed more energy than wild-type mice every $24 \mathrm{hr}$ (RC: $\mathrm{CK}_{1} \varepsilon^{+/+}=14.0 \pm$

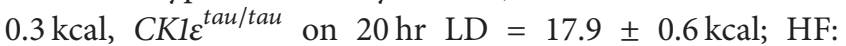
$C K 1 \varepsilon^{+/+}=17.9 \pm 0.9 \mathrm{kcal}, C K 1 \varepsilon^{\text {tau/tau }}$ on $20 \mathrm{hr} \mathrm{LD}=21.7 \pm$ $1.0 \%)$. The distribution of food intake during the light versus dark periods was altered in the CK1E mutants compared to wild-types (Figure 2(b)). On RC, $C K 1 \varepsilon^{-1-}$ mice consumed a greater proportion of their total daily calories during the dark period. In contrast, $C K 1 \varepsilon^{\text {tau/tau }}$ mice consumed much less diet during the dark period (Figure 2(b); $\mathrm{CK}_{1}{ }^{+/+}=80.9 \pm 1.0 \%$, $\mathrm{CK}_{1}{ }^{-/-}=83.8 \pm 1.0 \%$, and $\mathrm{CK1} \varepsilon^{\text {tau } / \text { tau }}=57.8 \pm 2.2 \%$ ). Thus, the diurnal rhythm in energy intake in $C K 1 \varepsilon^{\text {tau/tau }}$ mice was greatly attenuated on a $24 \mathrm{hr} \mathrm{LD}$ cycle. Interestingly, RCfed $C K 1 \varepsilon^{\text {taultau }}$ mice housed on a $20 \mathrm{hr}$ LD cycle consumed $73.1 \%$ of their total daily calories during dark period. This remained significantly lower than that of wild-type control mice but was improved compared to that of $C K 1 \varepsilon^{\text {tau/tau }}$ mice on a $24 \mathrm{hr}$ LD cycle (Figure 2(b)). On the HF diet, diurnal rhythms of food intake in mice of all three genotypes on a $24 \mathrm{hr}$ LD cycle were attenuated (Figure 2(b)). In particular, CKletau/tau mice on a $24 \mathrm{hr}$ LD cycle exhibited the greatest attenuation of diurnal feeding rhythms, consuming $49.1 \%$ calories during dark period. Surprisingly, HF-fed CKle $\varepsilon^{\text {taultau }}$ mice on a $20 \mathrm{hr}$ LD cycle displayed improved diurnal rhythms 


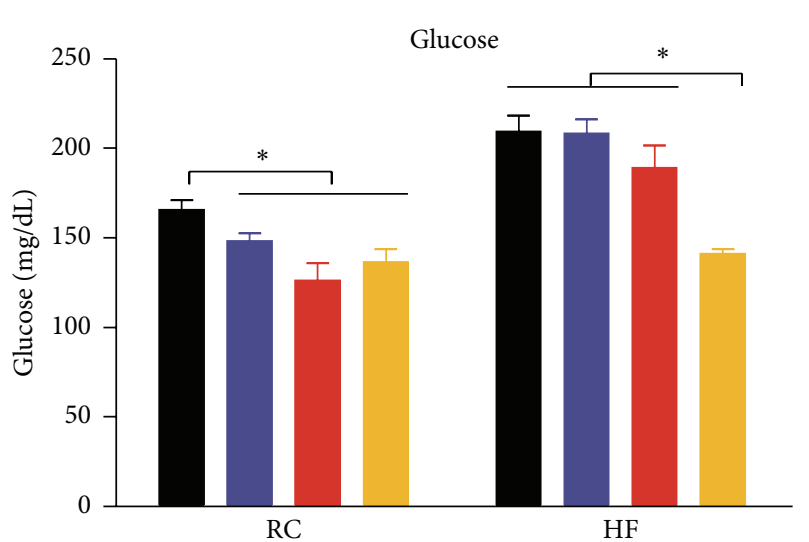

$\mathrm{WT}$
$\mathrm{KO}$
Tau

Tau20

(a)
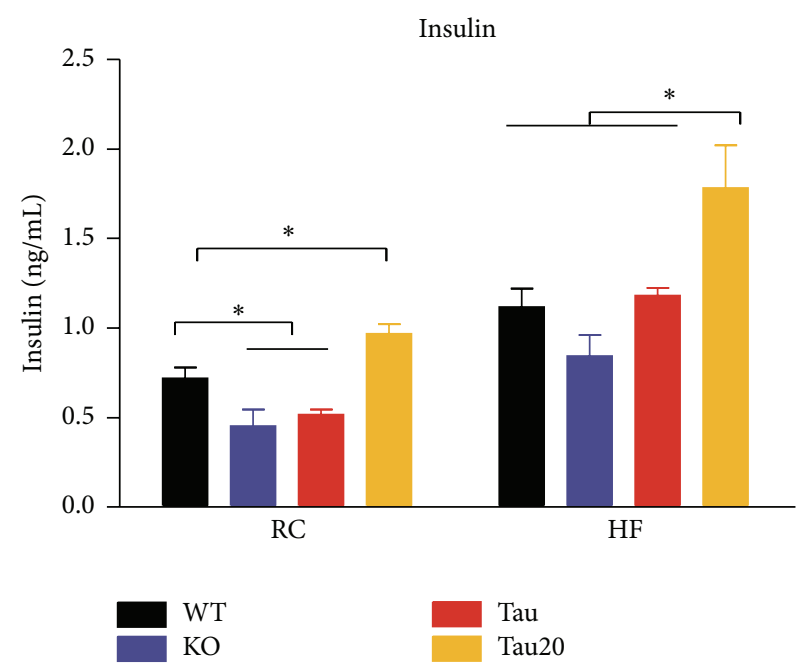

Tau

Tau20

(b)

FIgure 3: Altered glucose and insulin levels in CK1ع mutant mice. (a) Fasting serum glucose of mice fed either RC or HF diet. (b) Fasting serum insulin of mice fed either RC or HF diet. CK1 $\varepsilon^{+/+}$(white), $C K 1 \varepsilon^{-/-}$(blue), and CKl $\varepsilon^{\text {tau/tau }}$ (red) mice were on a 24 hr LD cycle; CK1 $\varepsilon^{\text {tau/tau }}$ mice represented in yellow were on a $20 \mathrm{hr}$ LD cycle. Mean values are presented for each group, with error bars representing SEM. Asterisks indicate significant differences between groups $(p<0.05)$.

of energy intake compared to the other groups on HF diet, consuming $64.6 \%$ of their total daily calories during the dark phase. No significant differences in absolute beam break activity levels (Figure 2(c)) and the activity patterns (Figure S2) were evident between wild-type mice and mutants on both RC and HF diet. Additionally, no differences in body temperature between genotype groups were observed under each diet condition (Figure S3).

\subsection{Altered Fasting Glucose and Insulin Levels in CK1ع} Mutants. We then examined fasting blood glucose and serum insulin levels in samples collected during the light phase. On the RC diet, both $C K 1 \varepsilon^{-/-}$and $C K 1 \varepsilon^{\text {tau/tau }}$ mice on a $24 \mathrm{hr}$ LD cycle, as well as CKletau/tau mice on $20 \mathrm{hr}$ LD cycle, had slight, but significant, reductions in fasting glucose compared to wild-type mice (Figure 3(a);CK1 $\varepsilon^{+/+}=165.7 \pm$ $5.4 \mathrm{mg} / \mathrm{dL}, C K 1 \varepsilon^{-/-}=148.3 \pm 4.3 \mathrm{mg} / \mathrm{dL}, C K 1 \varepsilon^{\text {tau } / \mathrm{tau}}=126.4 \pm$ $9.3 \mathrm{mg} / \mathrm{dL}$, and $C K 1 \varepsilon^{\text {tau } / \mathrm{tau}}$ on $\left.20 \mathrm{hr} \mathrm{LD}=136.6 \pm 7.1 \mathrm{mg} / \mathrm{dL}\right)$. On the HF diet, $C K 1 \varepsilon^{+/+}, C K 1 \varepsilon^{-/-}$, and $C K 1 \varepsilon^{\text {tau/tau }}$ mice on a $24 \mathrm{hr}$ LD cycle exhibited increased fasting glucose levels that did not significantly differ from one another. $C K 1 \varepsilon^{\text {tau/tau }}$ mutant mice on a $20 \mathrm{hr}$ LD cycle exhibited reduced fasting glucose levels compared to wild-types (Figure 3(a); CK1 $\varepsilon^{+/+}=$ $209.4 \pm 8.8 \mathrm{mg} / \mathrm{dL}$ and $C K 1 \varepsilon^{\text {tau/tau }}$ on $20 \mathrm{hr} \mathrm{LD}=141.1 \pm$ $2.5 \mathrm{mg} / \mathrm{dL})$.

Complex changes in fasting insulin levels were also observed. As shown in Figure 3(b), on RC diet and a $24 \mathrm{hr}$ LD cycle, both $C K 1 \varepsilon^{-/-}$and $C K 1 \varepsilon^{\text {tau/tau }}$ mice had lower levels of insulin than wild-type mice, whereas $C K 1 \varepsilon^{\text {tau/tau }}$ mice on a $20 \mathrm{hr}$ LD cycle exhibited higher fasting insulin levels than wild-type mice $\left(C K 1 \varepsilon^{+/+}=0.72 \pm 0.06 \mathrm{ng} / \mathrm{mL}\right.$,
$C K 1 \varepsilon^{-/-}=0.45 \pm 0.09 \mathrm{ng} / \mathrm{mL}, C K 1 \varepsilon^{\text {tau } / \mathrm{tau}}=0.52 \pm 0.03 \mathrm{ng} /$ $\mathrm{mL}$, and $C K 1 \varepsilon^{\text {tau } / \text { tau }}$ on $\left.20 \mathrm{hr} \mathrm{LD}=0.97 \pm 0.05 \mathrm{ng} / \mathrm{mL}\right)$. On HF diet, both $C K 1 \varepsilon^{-/-}$and $C K 1 \varepsilon^{\text {tau/tau }}$ mice on a $24 \mathrm{hr}$ LD cycle exhibited similar insulin levels. However, CK1 $\varepsilon^{\text {tau/tau }}$ mice on $20 \mathrm{hr}$ LD cycle exhibited a higher insulin level than wildtype mice on a $24 \mathrm{hr}$ LD cycle (Figure $3(\mathrm{~b}) ; C K 1 \varepsilon^{+/+}=1.12 \pm$ $0.10 \mathrm{ng} / \mathrm{mL}$ and $C K 1 \varepsilon^{\text {tau } / \mathrm{tau}}$ on $\left.20 \mathrm{hr} \mathrm{LD}=1.78 \pm 0.24 \mathrm{ng} / \mathrm{mL}\right)$.

3.4. Altered Glucose Tolerance in CK1E Mutants. To evaluate glucose utilization in the mutant mice, we performed both a glucose tolerance test and an insulin tolerance test. Because mice of different genotypes had different baseline levels, the data presented here were normalized by dividing the observed glucose value from the basal level of each genotype under each diet condition. On RC diet, $C K 1 \varepsilon^{\text {tau/tau }}$ mice on a $24 \mathrm{hr}$ LD cycle had a slower rate of glucose uptake than the other groups (Figure 4(a)), and the area under the curve (AUC) was higher in $C K 1 \varepsilon^{\text {tau/tau }}$ mice than $C K 1 \varepsilon^{+/+}$mice (Figure 4(c); CK1 $\varepsilon^{+/+}=100.0 \pm 4.9 \%$ and $C K 1 \varepsilon^{\text {tau } / \text { tau }}=$ $141.8 \pm 11.7 \%)$.

On HF diet, mice of all genotypes exhibited a reduced rate of glucose uptake compared to mice on RC diet (Figure 4(c)), and, among the groups, CK1 $\varepsilon^{\text {tau/tau }}$ mice on a $24 \mathrm{hr}$ LD cycle were slightly slower than wild-type mice, and CK1 $\varepsilon^{\text {tau/tau }}$ mice on a $20 \mathrm{hr}$ LD cycle were the most altered, having a significant and sustained reduction in glucose clearance (Figure 4(c); $\mathrm{CKl}^{+/+}=126.7 \pm 6.9 \%, C K 1 \varepsilon^{\text {tau } / \text { tau }}=148.5 \pm 7.5 \%$, and $C K 1 \varepsilon^{\text {tau/tau }}$ on $\left.20 \mathrm{hr} \mathrm{LD}=182.6 \pm 6.0 \%\right)$. No significant differences were observed under either diet condition from mice of any genotype during the ITT (Figures 4(d)-4(f)). 


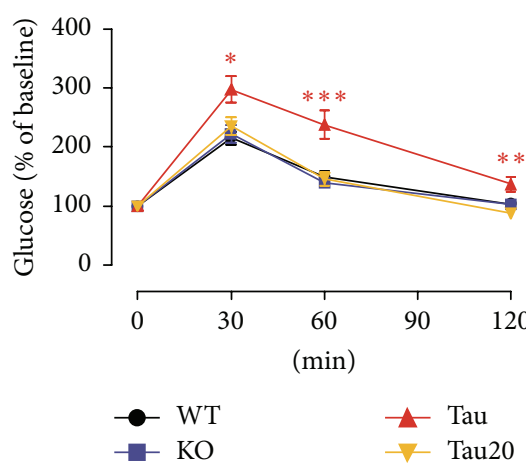

(a)

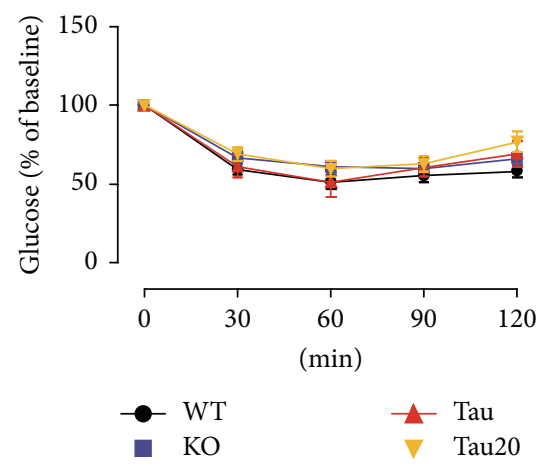

(d)

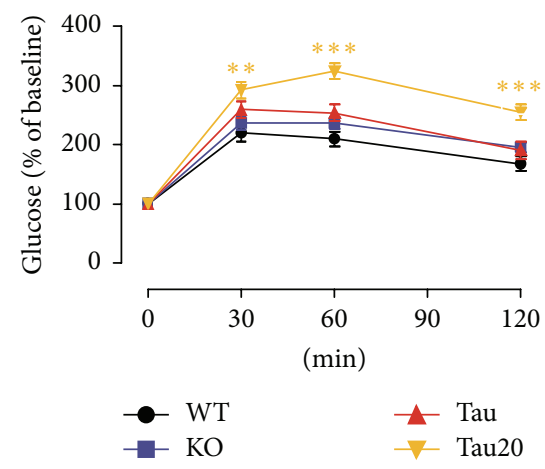

(b)

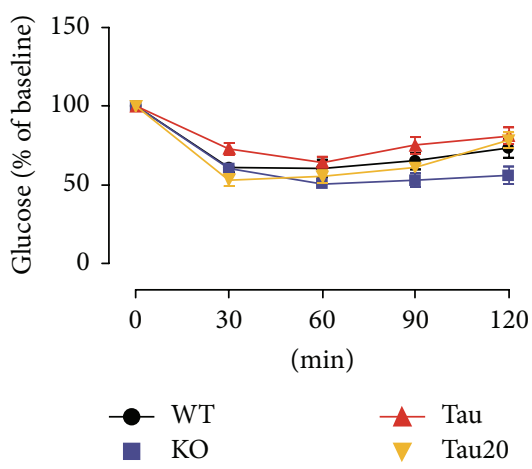

(e)

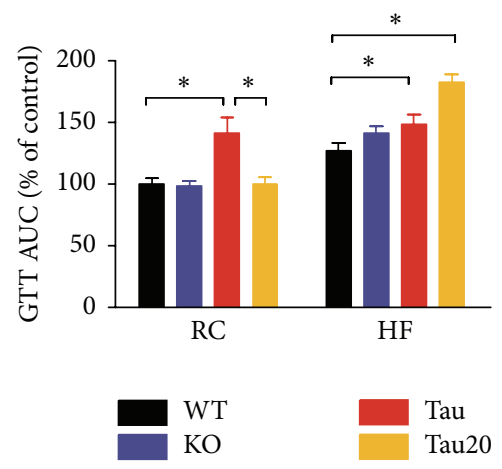

(c)

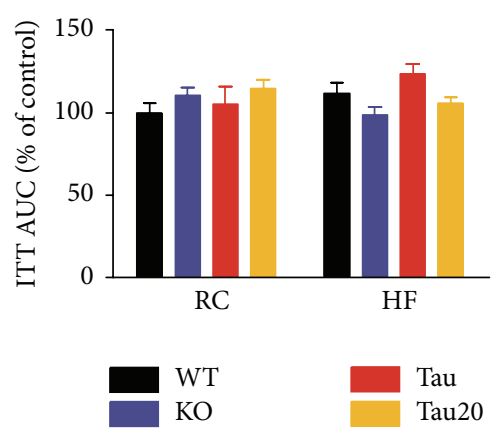

(f)

FIGURE 4: Alterations in GTT in CK1 $\varepsilon$ mutant mice. Top panel: GTT. Intraperitoneal GTT was performed in mice fed either RC (a) or HF (b) diet. (c) Area under the curve (AUC) of the GTT performed in (a) and (b). Bottom panel: ITT. Intraperitoneal ITT was performed in mice fed either RC (d) or HF (e) diet. (f) Area under the curve (AUC) of the ITT performed in (d) and (e). CK1 $\varepsilon^{+/+}$(white), CK1 ${ }^{-/-}$(blue), and CKle $\varepsilon^{\text {tau/tau }}$ (red) mice were on a $24 \mathrm{hr}$ LD cycle; CKle $\varepsilon^{\text {tau/tau }}$ mice represented in yellow were kept on a $20 \mathrm{hr}$ LD cycle. Mean values are presented for each group, with error bars representing SEM. Asterisks denote significant differences between mutant genotype and wild-type controls on the same diet $\left({ }^{*} p<0.05 ;{ }^{* *} p<0.01 ;{ }^{* * *} p<0.001\right)$.

\section{Discussion}

Using two genetic mouse models of $C K 1 \varepsilon$ disruption (i.e., knock-out $\mathrm{CKl \varepsilon}^{-/-}$null mice and knock-in $C K 1 \varepsilon^{\text {taultau }}$ mutant mice) under different diet conditions, we have demonstrated distinct effects of the circadian clock gene $C K 1 \varepsilon$ on body weight regulation and susceptibility to excess weight gain induced by HF diet. In particular, by maintaining CK1 $\varepsilon^{\text {taultau }}$ mice on a $20 \mathrm{hr}$ LD cycle, which more closely corresponds to their endogenous circadian period length and enables normal entrainment, we have generated evidence suggesting that proper entrainment and synchrony between internal circadian rhythms and the external environment may limit, or even protect against, the development of excess body weight gain induced by HF diet.

We found that both homozygous null and tau mutant mice had a reduced body weight, approximately $15 \%$ lower than wild-type mice on RC diet. The magnitude was close to the percentage $(18 \%)$ of reduced body mass reported in tau hamsters. But we believe that the body weight change

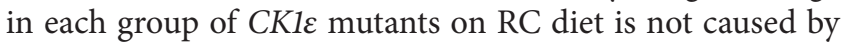
an accelerated circadian rate constant over physiological processes due to the discrepancy between impacts on body mass and circadian rhythms phenotype in $\mathrm{CK}_{1} \varepsilon^{-/-}$and $\mathrm{CK} 1 \varepsilon^{\text {tau/tau }}$ mice. We also noted that altered energy expenditure or intake does not appear to be the primary reason for the reduced body weight in CK1s mutant mice, because we did not observe increased activity levels or reduced food intake in mutants compared to the wild-type mice. We also did not observe increased body temperature in mutants compared to the wild-type mice, which is consistent with previous results [20].

The cause of the reduced body weight in CKle mutant mice is still unclear, but there are some possible mechanisms worth testing in the future. First of all, higher metabolic rates may be the main factor to determine the low body mass, which have been shown in both homozygous tau mutant hamsters and mice [19-21], although no study has been done

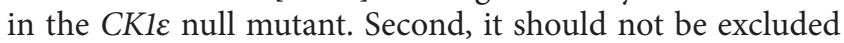
that alterations in development and cell growth might also

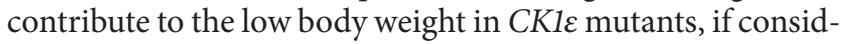
ering the slow-growth phenotype in yeast with a deletion of a CK1ع homolog gene [23], as well as the known function of CK1s in promoting cell growth $[24,25]$. Therefore, a further analysis of pathways involved in cell growth, such as Wnt and its intracellular effector $\beta$-catenin, in $C \mathrm{Kl}^{-/-}$and $C K 1 \varepsilon^{\text {taultau }}$ mice will help in testing this hypothesis. 
Studies have consistently demonstrated that misalignment of feeding behavior and circadian rhythms or a disrupted circadian clock can cause altered body weight regulation and result in the development of abnormalities consistent with the metabolic syndrome [10, 11, 26, 27]. In particular, a recent study demonstrated the harmful effects of chronic circadian disruption on metabolism in wild-type mice [14]. The mice were housed on a $20 \mathrm{hr}$ LD cycle, incongruous with their endogenous $24 \mathrm{hr}$ circadian period, and displayed significantly increased weight gain after 6 weeks on the altered LD cycle. Complementing this previous study, we took a different approach by studying CK1 $\varepsilon^{\text {tau/tau }}$ mice, which have an endogenous $20 \mathrm{hr}$ circadian period, in both a $24 \mathrm{hr}$ LD cycle and a $20 \mathrm{hr}$ LD cycle. Remarkably, we observed that the endogenous circadian period matched $20 \mathrm{hr}$ LD cycle protected against the HF diet-induced weight gain in $C K 1 \varepsilon^{\text {tau/tau }}$ mice. We found that HF-fed $C K 1 \varepsilon^{\text {tau/tau }}$ mice in a $24 \mathrm{hr} \mathrm{LD}$ cycle were no longer leaner than wildtypes as the tau mutant mice were on RC diet, and many of their metabolic parameters, such as absolute body weight, body weight gain, gonadal fat pad mass, and fasting blood glucose, were similar to those of wild-type mice on HF. However, when the LD cycle was adjusted to match their shortened endogenous circadian period, all these parameters were restored toward levels of wild-type mice on RC diet. Additionally, although the diurnal rhythms of food intake in HF-fed mice of all the genotypes were attenuated, which is similar to what was shown previously [28], HF-fed tau mice on a $20 \mathrm{hr}$ LD cycle displayed the least attenuation in diurnal rhythms of energy intake. However, unlike the altered body weight in wild-type mice on the shortened LD cycle [14], we did not observe any difference in body weight in CK1 $\varepsilon^{\text {tau/tau }}$ mice on RC diet between the $24 \mathrm{hr}$ LD cycle and endogenous circadian period matched $20 \mathrm{hr}$ LD cycle. The different responses to RC and HF diets in tau mice may be due to increased sensitivity to diet-induced weight gain on a metabolically "challenging" $\mathrm{HF}$ diet, compared to the RC diet, in the $C K 1 \varepsilon^{\text {tau/tau }}$ mice. Another possibility is that we only monitored body weight in CKle $\varepsilon^{\text {tau/tau }}$ mice in a $20 \mathrm{hr}$ LD cycle for 6 weeks during adulthood; we do not know if a longer exposure to an endogenous circadian period matched $\mathrm{LD}$ cycle or if rearing in $20 \mathrm{hr} \mathrm{LD}$ cycle from birth would restore the body weight in RC-fed CK1 $\varepsilon^{\text {tau/tau }}$ mice. Further experiments are needed to address these questions.

It has recently been reported that CK1s tau mutant hamsters are protected against the development of cardiomyopathy and renal disease by adjusting the environmental LD cycle to match their shortened endogenous circadian period [29]. Both the present study and previous experiments $[14,29]$ have demonstrated that certain metabolic and pathological abnormalities may be restored or prevented by optimizing the LD cycle and suggest that strategies designed to synchronize and match internal circadian cycles with the external environment may be useful in limiting or preventing the development of metabolic abnormalities. Synchronizing internal circadian cycles with the external environment has at least two beneficial effects on circadian organization: proper entrainment and resonance between environmental and internal circadian period length, which need not be mutually exclusive. The present study could not distinguish between these two effects, and future work utilizing entrainmentspecific or period-specific mutants would be necessary to do so.

In the present study, we had some discrepant observations. For example, HF-fed $C K 1 \varepsilon^{\text {tau/tau }}$ mice on a $20 \mathrm{hr}$ LD cycle had significantly lower body weight, but higher energy intake. This might be an interacting effect of a higher metabolic rate and a restoration of the LD cycles matching the endogenous period on the HF diet-induced weight gain. An improved alignment of the endogenous rhythms with the environmental LD cycle may improve the temporal coordination between feeding and metabolism, expending the energy intake at the correct time more efficiently. High metabolic rate alone or correct LD cycle alone may not act as effectively as in HF-fed $C K 1 \varepsilon^{\text {tau } / \text { tau }}$ mice on a $20 \mathrm{hr}$ LD cycle. Another discrepancy in the results is that the HF-fed CKletau/tau mice on a $20 \mathrm{hr}$ LD cycle have lower fasting glucose but higher AUG in GTT. Although in many cases a reduced glucose level is associated with improved GTT, or a high level of glucose is associated with impaired GTT, a coexistence of both low glucose level and impaired GTT sometimes happens. One example is gene pancreaticderived factor (PANDER), which was recently found to be a novel hormone regulating glucose levels via interaction with both the liver and the endocrine pancreas. Although still glucose intolerant, PANDER-deficient mice fed a HF diet are protected from HF diet-induced hyperglycemia because of the decreased expression of the gluconeogenic genes PEPCK and G6Pase and the reduced glucose production in the liver [30]. Although it is still unclear what the exact mechanism is for HF-fed CK1 $\varepsilon^{\text {tau/tau }}$ mice on a $20 \mathrm{hr}$ LD cycle showing both low glucose level and GTT intolerance in the present study, it is possible that the tau mutation affects certain gene(s) which function similarly as PANDER or its receptor.

\section{Conclusions}

In conclusion, we have demonstrated that differences in body weight regulation and the response to a HF diet challenge exist in two different mouse mutants of CK1 1 on a $24 \mathrm{hr} \mathrm{LD}$ cycle, as well as CK1 $\varepsilon^{\text {tau/tau }}$ mice on a $20 \mathrm{hr}$ LD cycle that matches their endogenous circadian period. Both $\mathrm{CK1} \varepsilon^{-/-}$ and $C K 1 \varepsilon^{\text {tau/tau }}$ mice had reduced body weights on RC diet despite similar overall caloric consumption and daily activity levels. On a HF diet, however, CK1 $\varepsilon^{\text {tau/tau }}$ mice on a $20 \mathrm{hr} \mathrm{LD}$ cycle were protected against the development of excess body weight gain induced by HF diet. These findings may provide unique insights for future strategies of obesity management, which involve the nutrient composition of the diet, the properties and principles of the circadian clock system, and the interactions between these two factors in determining the metabolic responses.

\section{Competing Interests}

The authors wish to disclose the absence of financial and pharmaceutical company support and off-label or 
investigational use of drugs or devices for this study. Martha H. Vitaterna has participated in research supported in part by Merck \& Co., Inc., and in a study funded by Institut de Recherches Internationales Servier, but the experiments and results reported in this paper were not supported by either of these. Fred W. Turek has received consultant fees from Vanda Pharmaceuticals, Inc., and the Ingram Barge Company. The other authors have disclosed the absence of any financial competing interests.

\section{Acknowledgments}

Keith C. Summa was supported in part by the National Center for Research Resources (NCRR) and the National Center for Advancing Translational Sciences (NCATS), National Institutes of Health (NIH), through a Northwestern University Clinical and Translational Sciences Institute Predoctoral Training Grant (8UL1TR000150).

\section{References}

[1] J. S. Takahashi, H.-K. Hong, C. H. Ko, and E. L. McDearmon, "The genetics of mammalian circadian order and disorder: implications for physiology and disease," Nature Reviews Genetics, vol. 9, no. 10, pp. 764-775, 2008.

[2] C. H. Ko and J. S. Takahashi, "Molecular components of the mammalian circadian clock," Human Molecular Genetics, vol. 15, no. 2, pp. R271-R277, 2006.

[3] C. B. Green, J. S. Takahashi, and J. Bass, "The meter of metabolism," Cell, vol. 134, no. 5, pp. 728-742, 2008.

[4] S. Panda, M. P. Antoch, B. H. Miller et al., "Coordinated transcription of key pathways in the mouse by the circadian clock," Cell, vol. 109, no. 3, pp. 307-320, 2002.

[5] R. D. Rudic, P. McNamara, A.-M. Curtis et al., "BMAL1 and CLOCK, two essential components of the circadian clock, are involved in glucose homeostasis," PLoS Biology, vol. 2, no. 11, article e377, 2004.

[6] L. Di Lorenzo, G. De Pergola, C. Zocchetti et al., "Effect of shift work on body mass index: results of a study performed in 319 glucose-tolerant men working in a Southern Italian industry," International Journal of Obesity, vol. 27, no. 11, pp. 1353-1358, 2003.

[7] B. Karlsson, A. Knutsson, and B. Lindahl, "Is there an association between shift work and having a metabolic syndrome? Results from a population based study of 27,485 people," Occupational and Environmental Medicine, vol. 58, no. 11, pp. 747-752, 2001.

[8] Y. Suwazono, M. Dochi, K. Sakata et al., "A longitudinal study on the effect of shift work on weight gain in male Japanese workers," Obesity, vol. 16, no. 8, pp. 1887-1893, 2008.

[9] F. A. J. L. Scheer, M. F. Hilton, C. S. Mantzoros, and S. A. Shea, "Adverse metabolic and cardiovascular consequences of circadian misalignment," Proceedings of the National Academy of Sciences of the United States of America, vol. 106, no. 11, pp. 4453-4458, 2009.

[10] F. W. Turek, C. Joshu, A. Kohsaka et al., "Obesity and metabolic syndrome in circadian clock mutant mice," Science, vol. 308, no. 5724, pp. 1043-1045, 2005.

[11] S. Yang, A. Liu, A. Weidenhammer et al., "The role of mPer2 clock gene in glucocorticoid and feeding rhythms," Endocrinology, vol. 150, no. 5, pp. 2153-2160, 2009.
[12] K. A. Lamia, K.-F. Storch, and C. J. Weitz, "Physiological significance of a peripheral tissue circadian clock," Proceedings of the National Academy of Sciences of the United States of America, vol. 105, no. 39, pp. 15172-15177, 2008.

[13] S. Shimba, N. Ishii, Y. Ohta et al., "Brain and muscle Arntlike protein-1 (BMAL1), a component of the molecular clock, regulates adipogenesis," Proceedings of the National Academy of Sciences of the United States of America, vol. 102, no. 34, pp. 12071-12076, 2005.

[14] I. N. Karatsoreos, S. Bhagat, E. B. Bloss, J. H. Morrison, and B. S. McEwen, "Disruption of circadian clocks has ramifications for metabolism, brain, and behavior," Proceedings of the National Academy of Sciences of the United States of America, vol. 108, no. 4, pp. 1657-1662, 2011.

[15] A. S. I. Loudon, Q. J. Meng, E. S. Maywood, D. A. Bechtold, R. P. Boot-Handford, and M. H. Hastings, "The biology of the circadian CK1s tau mutation in mice and Syrian hamsters: a tale of two species," Cold Spring Harbor Symposia on Quantitative Biology, vol. 72, pp. 261-271, 2007.

[16] P. L. Lowrey, K. Shimomura, M. P. Antoch et al., "Positional syntenic cloning and functional characterization of the mammalian circadian mutation tau," Science, vol. 288, no. 5465, pp. 483-491, 2000.

[17] M. R. Ralph and M. Menaker, "A mutation of the circadian system in golden hamsters," Science, vol. 241, no. 4870, pp. 1225$1227,1988$.

[18] Q.-J. Meng, L. Logunova, E. S. Maywood et al., "Setting clock speed in mammals: the CK1ع tau mutation in mice accelerates circadian pacemakers by selectively destabilizing PERIOD proteins," Neuron, vol. 58, no. 1, pp. 78-88, 2008.

[19] R. J. Lucas, J. A. Stirland, Y. N. Mohammad, and A. S. I. Loudon, "Postnatal growth rate and gonadal development in circadian tau mutant hamsters reared in constant dim red light," Journal of Reproduction and Fertility, vol. 118, no. 2, pp. 327-330, 2000.

[20] M. Oklejewicz, R. A. Hut, S. Daan, A. S. I. Loudon, and A. J. Stirland, "Metabolic rate changes proportionally to circadian frequency in tau mutant Syrian hamsters," Journal of Biological Rhythms, vol. 12, no. 5, pp. 413-422, 1997.

[21] M. Oklejewicz, I. Pen, G. C. R. Durieux, and S. Daan, "Maternal and pup genotype contribution to growth in wild-type and tau mutant Syrian hamsters," Behavior Genetics, vol. 31, no. 4, pp. 383-391, 2001.

[22] R Development Core Team, R: A Language and Environment for Statistical Computing, R Foundation for Statistical Computing, Vienna, Austria, 2011.

[23] K. J. Fish, A. Cegielska, M. E. Getman, G. M. Landes, and D. M. Virshup, "Isolation and characterization of human casein kinase I epsilon (CKI), a novel member of the CKI gene family," The Journal of Biological Chemistry, vol. 270, no. 25, pp. 14875-14883, 1995.

[24] J. S. Boehm, J. J. Zhao, J. Yao et al., "Integrative genomic approaches identify IKBKE as a breast cancer oncogene," Cell, vol. 129, no. 6, pp. 1065-1079, 2007.

[25] W. S. Yang and B. R. Stockwell, "Inhibition of casein kinase 1-epsilon induces cancer-cell-selective, PERIOD2-dependent growth arrest," Genome Biology, vol. 9, no. 6, article R92, 2008.

[26] D. M. Arble, J. Bass, A. D. Laposky, M. H. Vitaterna, and F. W. Turek, "Circadian timing of food intake contributes to weight gain," Obesity, vol. 17, no. 11, pp. 2100-2102, 2009.

[27] M. Garaulet, P. Gómez-Abellán, J. J. Alburquerque-Béjar, Y. Lee, J. M. Ordovás, and F. A. Scheer, “Timing of food intake predicts 
weight loss effectiveness," International Journal of Obesity, vol. 37, no. 4, pp. 604-611, 2013.

[28] A. Kohsaka, A. D. Laposky, K. M. Ramsey et al., "High-fat diet disrupts behavioral and molecular circadian rhythms in mice," Cell Metabolism, vol. 6, no. 5, pp. 414-421, 2007.

[29] T. A. Martino, G. Y. Oudit, A. M. Herzenberg et al., "Circadian rhythm disorganization produces profound cardiovascular and renal disease in hamsters," American Journal of PhysiologyRegulatory Integrative and Comparative Physiology, vol. 294, no. 5, pp. R1675-R1683, 2008.

[30] C. E. Robert-Cooperman, C. G. Wilson, and B. R. Burkhardt, "PANDER KO mice on high-fat diet are glucose intolerant yet resistant to fasting hyperglycemia and hyperinsulinemia," FEBS Letters, vol. 585, no. 9, pp. 1345-1349, 2011. 

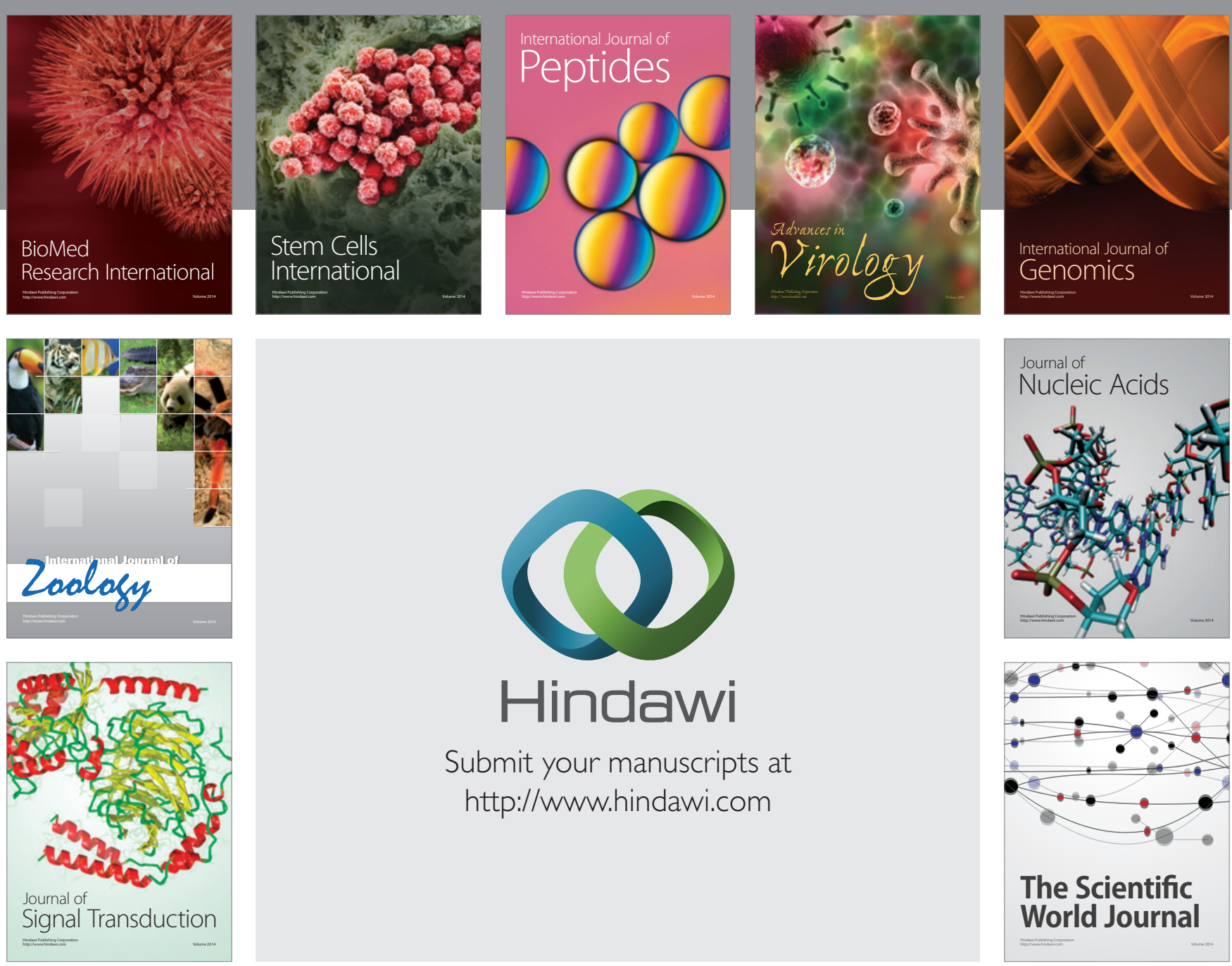

Submit your manuscripts at

http://www.hindawi.com
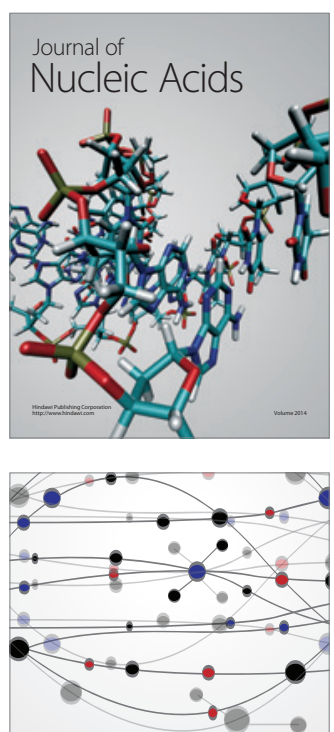

The Scientific World Journal
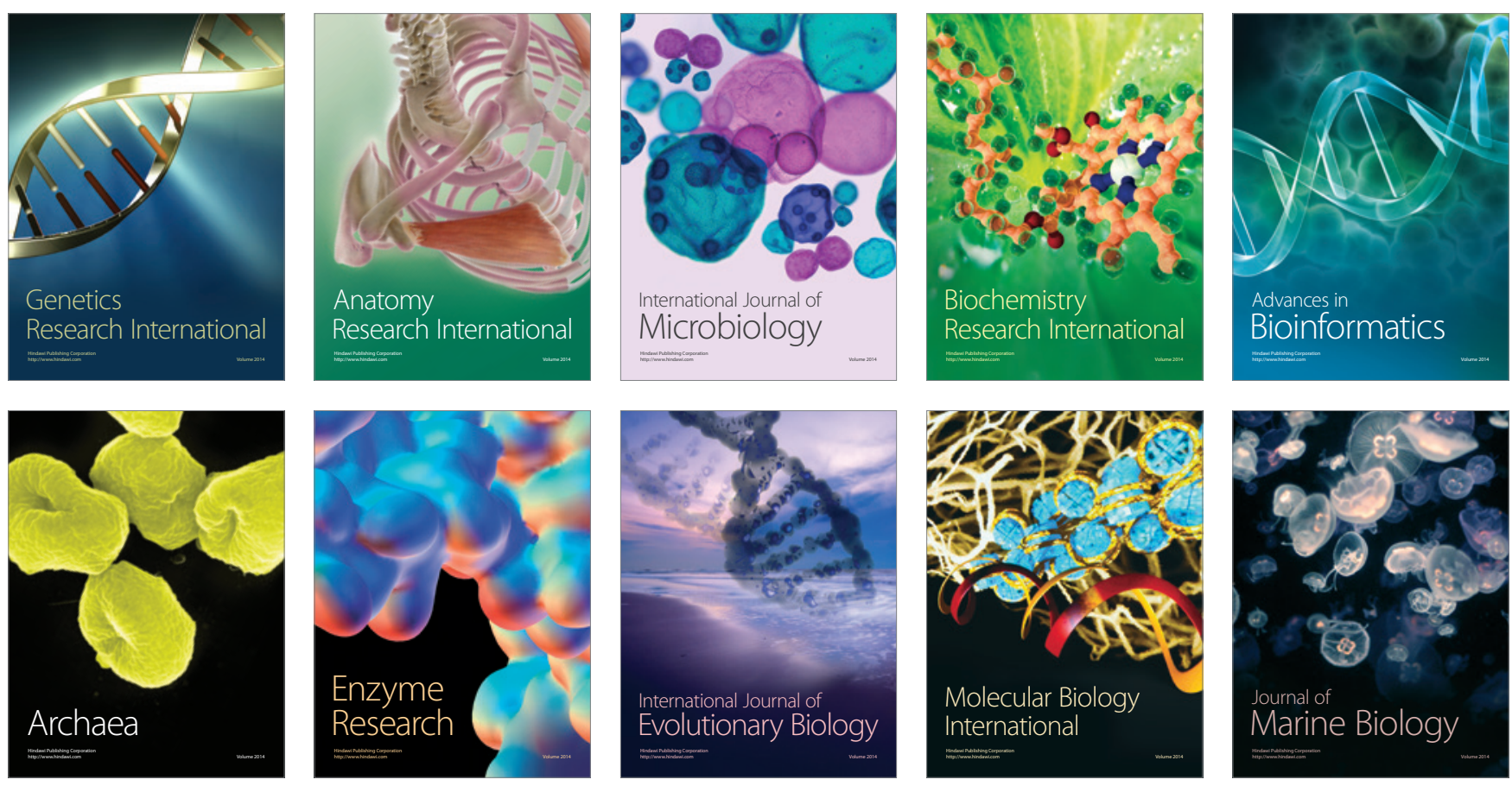